\title{
A formação distorcida de preços administrados na experiência brasileira recente
}

\author{
ARTHUR BARRIONUEVO*
}

RESUMO: Este artigo discute a necessidade de ajuste do preço microeconômico no Brasil no final do primeiro governo Dilma Rousseff (2011-14). O controle de preço é feito por diferentes meios, pelos três níveis de governo, federal, estadual e municipal. Ele inclui serviços regulados por agências nos setores de infraestrutura, como energia elétrica, telefonia fixa e estradas pedagiadas, o controle direto dos preços de empresas estatais, como produtos de petróleo, ou através de legislação específica, como nos serviços de saúde. No entanto, os diferentes níveis de governo, eventualmente, distorcem os preços através de medidas arbitrárias, por objetivos políticos de curto prazo, desconsiderando as instituições destinadas a defini-los. A ênfase do trabalho é avaliar a evolução destes preços durante o último mandato presidencial e a dificuldade de manter os reais preços administrados em tal contexto.

PALAVRAS-CHAVE: Produção; precificação; estrutura de mercado; política pública; utilidades elétricas; telecomunicações; utilidades; política.

ABSTRACT: The distorted formation of administered prices in recent Brazilian experience. This article discusses the necessity for microeconomic price adjustment in Brazil at the end of the first government Dilma Rousseff (2011-2014). The price control in Brazil is done by different means, by the three levels of government, federal, state and municipal. It includes services regulated by agencies in infrastructure sectors such as electricity, fixed telephony and road tolls; the direct control of state enterprises prices, as in the case of petroleum products, or through specific legislation as in health services. However, the different levels of government eventually distort prices through arbitrary measures, given short-term political objectives, disregarding the institutions designed to define them. The emphasis of the paper is to evaluate the evolution of these prices during the last presidential term and the difficulty of maintaining realistic administered prices in such a context.

KEYWORDS: production; pricing; market structure; public policy; electric utilities; telecommunications; utilities; government policy.

JEL Classification; L11; L38; L94; L96; L97; L98;

\footnotetext{
* Professor de Economia da Fundação Getulio Vargas (FGV-SP) nas Escolas de Administração e de Direito. E-mail: Arthur.barrionuevo@fgv.br. Submetido: 18/agosto/2014; Aprovado: 12/setembro/2014.
} 


\section{INTRODUÇÃO}

O presente trabalho discute a necessidade de ajuste de preços microeconômicos no Brasil de hoje. Em particular, a urgência do ajuste e as dificuldades para realizá-lo. $O$ viés deste autor faz com que a ênfase do trabalho recaia sobre as dificuldades de realizar - e manter - o ajuste de preços, portanto, discutir a formação destes preços no contexto brasileiro recente, deixando a urgência do ajuste em segundo plano.

Note-se que "preços administrados" podem ser fixados ou diretamente pelos governos através de sua posição de controlador acionário de um monopólio legal (ou de fato, como o da Petrobras), ou via processo regulatório, onde, em tese, regras definidas deveriam balizar a formação de preços, normalmente por intermédio de órgãos técnicos independentes.

No entanto, na prática, o processo regulatório pode ser distorcido por intervenção do Executivo, seja por captura do regulador, seja através da edição de normas legais que sobrepassam as competências do regulador (em geral via Medidas Provisórias) permitindo ao Poder Executivo definir os preços administrados.

Assim, para a discussão do ajuste de preços, na próxima seção serão abordados os motivos que - em tese - fundamentam o controle de preços, tendo em vista o bem-estar econômico. São apresentadas as teorias sobre regulação de monopólios e os problemas de fixar preços para o usuário final, tendo em vista a assimetria de informação regulador/regulado. São vistas então as alternativas para o controle de preços, regulação de taxa de retorno, price-cap, ou licitação de monopólio, e como a tendência atual é a de incentivar a competição ao invés de controlar preços ao consumidor. DiscuteM-se também os fatores que, no Brasil, têm motivado a intervenção direta sobre os preços por parte do Poder Executivo, normalmente ligadas a fatores de curto prazo, sejam eles macroeconômicos, como o represamento da inflação, seja o estímulo ao consumo de bem ou serviço em função do ciclo eleitoral.

$\mathrm{Na}$ terceira seção são analisados a evolução dos preços administrados no governo Dilma Rousseff (2011-2014) e seu desequilíbrio. A situação é comparável aos anos 1980, em que "defasagens" de preços administrados, em particular dos serviços de utilidade pública, foram recorrentes (e "tarifaços” em planos anti-inflacionários)1.

Finalmente, a última seção discute quais os caminhos para tratar do represamento no curto e no longo prazo, considerando a necessidade de alterar a maneira com que são fixados os preços administrados, fortalecendo o processo regulatório e abrindo para a competição setores que hoje são monopólios de fato de empresas estatais.

\section{FUNDAMENTOS DA “ADMINISTRAÇÃO DE PREÇOS”}

A teoria econômica convencionalmente considera adequada a intervenção estatal para a fixação de preços quando existem "falhas de mercado" que permitem

\footnotetext{
${ }^{1}$ É uma situação vivenciada também no pré-1964, que igualmente se caracterizou por forte descontrole inflacionário.
} 
um aumento do bem-estar econômico via a intervenção estatal para minimizá-las. As falhas de mercado são condições que afastam o funcionamento do mercado do tipo ideal da "concorrência perfeita".

Entretanto, este afastamento é a situação normal nas economias realmente existentes, onde os agentes econômicos têm racionalidade limitada, a informação é imperfeita e os mercados apresentam características oligopolistas ou até monopolistas, contratos e direitos de propriedade são incompletos, etc. Assim, a propriedade de haver a intervenção, ou não, depende, além da avaliação ${ }^{2}$ da gravidade das "falhas de mercado" existentes, da ideologia dos governantes em exercício.

No Brasil, o IPCA, que é o índice oficial de inflação, atribui um grande peso $(23,26 \%)$ aos "preços administrados", com mostra a Tabela 1 a seguir.

\begin{tabular}{l|l} 
Tabela 1: Estrutura do IPCA — Preços Administrados \\
\hline Preços Administrados & $23,26 \%$ \\
\hline Taxa de água e esgoto & $1,55 \%$ \\
Gás de botijão & $1,09 \%$ \\
Gás encanado & $0,08 \%$ \\
Energia elétrica residencial & $2,67 \%$ \\
Ônibus urbano & $2,63 \%$ \\
Táxi & $0,38 \%$ \\
Trem & $0,06 \%$ \\
Ônibus intermunicipal & $0,72 \%$ \\
Ônibus interestadual & $0,24 \%$ \\
Metrô & $0,07 \%$ \\
Transporte hidroviário & $0,01 \%$ \\
Emplacamento e licença & $0,99 \%$ \\
Multa & $0,04 \%$ \\
Pedágio & $0,12 \%$ \\
Gasolina & $3,86 \%$ \\
Óleo diesel & $0,13 \%$ \\
Gás veicular & $0,11 \%$ \\
Produtos farmacêuticos & $3,48 \%$ \\
Plano de saúde & $3,14 \%$ \\
Jogos de azar & $0,38 \%$ \\
Correio & $0,01 \%$ \\
Telefone fixo & $1,37 \%$ \\
Telefone público & $0,12 \%$ \\
\hline Font: IBGE va Tendencas Consutora & 15 \\
\hline
\end{tabular}

Fonte: IBGE via Tendências Consultoria Integrada.

\footnotetext{
${ }^{2}$ Portanto de um cálculo de custo-benefício sobre as distorções ocasionada pela própria intervenção estatal.
} 
Como se pode observar, os itens controlados são, principalmente, serviços de utilidade pública, como: (i) água e saneamento; (ii) comunicações (correio, telefone público e telefonia fixa); (iii) energia, que engloba energia elétrica residencial, gás (encanado, de botijão e veicular), gasolina, óleo diesel e (iv) transportes urbanos (metrô, ônibus urbano, trem e táxi) ou interurbanos (ônibus interestadual, ônibus intermunicipal, pedágio e multa). Incluem também serviços sociais, tais como planos de saúde e produtos farmacêuticos.

Vickers e Yarrow (1988) e Phillips (1993) mostram que as autoridades governamentais (nos EUA e na Europa Ocidental) há muito ${ }^{3}$ se preocupam com as condições de oferta de tais serviços, seja intervindo de maneira direta, via o controle acionário das empresas que fornecem tais serviços, seja através da regulação de tais atividades.

Os motivos econômicos que fundamentam tal intervenção buscam anular os efeitos de "falhas de mercado" presentes na prestação de tais serviços. Duas falhas são especialmente relevantes: (1) poder de monopólio das empresas prestadoras de serviços e (2) externalidades ${ }^{4}$.

O poder de monopólio é originado da existência de fortes barreiras à entrada em muitos destes mercados (ressalta-se entre elas o alto investimento, que é sunk $\operatorname{cost}^{5}$ por envolver ativos muito específicos, a existência de ativos não replicáveis em termos econômicos, que são essential facilities, e grandes economias de escala e escopo). Todos estes fatores limitam o número de prestadores, tornando tais mercados monopólios ou oligopólios "naturais", com capacidade de aumentar preços.

A segunda falha de mercado mencionada, as “externalidades", são custos ou benefícios que não oneram ou não favorecem o agente que os causa. Existem externalidades negativas, como a poluição, que são sancionadas para reduzi-las. As externalidades positivas, de outro lado, interessam ao Estado, pois o ganho social destas atividades é maior do que a soma dos seus ganhos privados.

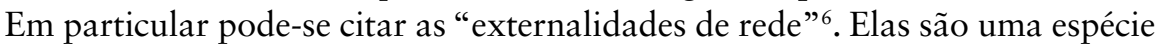
de "economias de escala" do lado do consumo. Pode-se citar como exemplo a telefonia celular, em que cada novo assinante traz um benefício aos assinantes já existentes ${ }^{7}$ sem que eles paguem nada pelo benefício adicional. Assim, o ganho do

\footnotetext{
${ }^{3}$ As agências reguladoras começam a se generalizar nos EUA a partir dos anos 1870. Na Europa Ocidental houve um movimento de estatização dos serviços de infraestrutura no pós-guerra.

${ }^{4}$ Uma terceira falha, a assimetria de informação, é particularmente relevante para o setor de saúde (vide Armstrong, M.; Cowan, S. Vickers, 1994) como planos de saúde e produtos farmacêuticos, pois o paciente não detém a mesma informação que os prestadores de serviço. Foi ignorada por ser menos importantes para os outros serviços.

${ }^{5}$ Um ativo tem características de sunk cost se a necessidade de empregá-lo em outro ramo de atividade faz com que perca boa parte de seu valor. Já essential facility é um ativo que é essencial para que uma empresa possa prestar determinado serviço e não é economicamente viável replicá-lo, p.ex., o leito de uma estrada de ferro no setor ferroviário.

${ }^{6}$ Veja-se Liebowitz e Margolis (2002).

${ }^{7}$ Os antigos assinantes poderão acessar um novo assinante que pode ser alguém de seu relacionamento, ou um novo prestador de algum serviço utilizado por eles.
} 
conjunto da sociedade é maior do que o ganho privado do novo assinante e da empresa que presta o serviço.

A existência de externalidades de rede é fundamento das diversas políticas de "universalização" de serviços de infraestrutura, tais como telefonia fixa, telefonia móvel, internet banda larga, eletrificação rural, estradas vicinais, etc. Para atingir seus objetivos de universalização o Estado lança mão de subsídios ou de preços com "subsídios cruzados" (embora esses, normalmente, gerem distorções na economia).

Os instrumentos utilizados pelas autoridades ${ }^{8}$ para sanar as falhas de mercado e estimular a difusão dos serviços incluem, além do controle de preços (que pode ser ao usuário final, ou, como é a tendência atualmente, de algum insumo, como p.ex. o valor de acesso à rede de um concorrente, no caso da telefonia), o controle de entrada e saída de novos prestadores de serviços e o controle de padrões mínimos de qualidade. Note-se que o controle de entrada e saída impacta indiretamente o preço final do serviço. O controle de preços é analisado a seguir.

\section{Efeitos do Controle de Preços}

A fixação de preços para o usuário final tem efeito sobre as seguintes variáveis econômicas:

1. Equilíbrio econômico-financeiro da empresa, que necessita cobrir seus custos fixos e o custo do seu capital;

2. Incentivo à eficiência produtiva - se qualquer aumento de eficiência é imediatamente repassado ao preço, a empresa não será incentivada a aumentar sua produtividade;

3. Incentivo ao investimento, para que a empresa possa adequar a sua capacidade produtiva ao crescimento da demanda.

É difícil definir o preço adequado para maximizar o ganho da sociedade, incentivando a eficiência e o investimento, pois existe uma assimetria de informação entre o regulador (ou o governo) e a empresa regulada, que tem maior conhecimento sobre custos e operações. Preços baixos, ainda que cubram os custos totais da empresa, não incentivam o investimento. Do mesmo modo, preços que são reajustados de forma frequente, de acordo com seus custos marginais, não incentivam o aumento da eficiência.

Além disso, o controle dos preços ao usuário final enfrenta a situação da empresa multiproduto, que através de um processo de produção conjunta (p.ex. o refino do petróleo, telefonia, etc.) gera um conjunto de produtos, cujos custos em boa parte não podem ser individualizados. Assim, há que decidir também qual será o preço relativo para cada um destes produtos.

As metodologias comumente utilizadas para realizar o controle de preços ao usuário final são:

\footnotetext{
${ }^{8}$ Viscusi, W.; Harrington, J. e Vernon, J. Economics of Regulation and Antitrust. Cambridge: Massachusetts, MIT Press, 2005, cap. 10.
} 
a) Regulação da taxa de retorno;

b) Price-cap;

c) Licitação de concessão do serviço (leilão de monopólio).

A regulação da taxa de retorno, e portanto de um preço que garanta esta taxa, que foi usual até os anos 1970, apresenta um conjunto de problemas:

- Qual é taxa de retorno adequada?

- Qual a base de capital para aplicar a taxa?

- A empresa tomará decisões para alterar sua base de capital para influenciar os preços? Quais as distorções resultantes?

Um dos problemas gerados na escolha da taxa de retorno permitida (s) é o chamado efeito Averch-Johnson. Através de um modelo, estes autores mostram que quando $s>r$, que é a taxa de retorno do capital no mercado, a empresa reage estrategicamente aumentando sua base de capital. Assim, a empresa tem ganho estratégico ao influenciar o preço permitido. Desse modo, a regulação aumenta o produto, mas existe trade-off entre eficiência produtiva e alocativa.

Uma variante seria a de fixar o preço e permitir que o retorno fosse definido pela própria empresa. Todavia, como mostram Laffont e Tirole (1993), há um trade-off para o regulador: se fizer o preço igual ao custo marginal, atinge eficiência alocativa (não há incentivo para excesso de investimento), mas não existe incentivo para reduzir custos. De outro lado, se fizer nível fixo de preço, gera incentivo para reduzir custos, mas não a eficiência alocativa.

A segunda metodologia, de regulação via teto de preços (price-cap), é uma tentativa de resolver o trade-off apontado acima. Este método supõe a fixação de um preço inicial, seja pelo regulador, seja por um processo licitatório, e este preço é reajustado em períodos determinados (p.ex. anualmente) por algum índice de preços, todavia é descontado deste reajuste um fator de aumento esperado de produtividade (o fator $\mathrm{x}$ ) que se espera que uma empresa típica daquele setor deva atingir no tempo entre os reajustes. Depois de um certo número de períodos é realizada uma revisão do preço de acordo com os custos efetivos apurados e o preço é revisado para cima ou para baixo, e volta a ser reajustado todo ano. Desse modo, gera-se um incentivo para a redução de custos e para evitar o excesso de investimentos.

A última forma mencionada é a possibilidade do regulador provocar ou utilizar a competição "pelo mercado", ao invés de "no mercado", para atingir um preço resultante do processo licitatório que se aproxime de um preço competitivo. A licitação da concessão (ou do franchising) é um leilão do monopólio para prestar o serviço. É utilizado em situações em que existe um “monopólio natural”. Tem também os seus problemas: conluio na licitação e o handover de ativos quando termina o prazo da concessão.

Uma alternativa, em lugar da licitação definir o preço, é o de yardstick competition, em que se utilizam os custos de empresas que prestam o mesmo serviço em outras regiões do país para reajustar os preços de cada empresa. Aqui os pro- 
blemas são os de conseguir regiões suficientemente homogêneas para possibilitar uma comparação adequada.

\section{Regulação para Manter Competição Efetiva}

A regulação pode atuar também como meio para garantir a competição em mercados onde a tendência seria o monopólio. Neste caso ela pode ser fundamental para manter liberdade de entrada e a garantia de interoperabilidade do sistema. Apenas a lei antitruste pode ser insuficiente para manter a concorrência. As soluções competitivas garantidas pela regulação podem:

a) Manter os mercados contestáveis e garantir a função da competição potencial. Esta, por sua vez, diminui a necessidade de regulamentação.

b) A competição funciona como mecanismo de incentivo, aumentando a informação do regulador e reduzindo a " $x$-inefficiency".

c) A competição no caso de integração vertical e networks, tem como pre condição a separação vertical ou regras de acesso (essencial para telecomunicações, gás e energia elétrica).

Assim, mecanismos para garantir preços que possam trazer benefícios à sociedade existem. Entretanto, tais mecanismos funcionam em um mundo concreto, onde existe captura dos responsáveis pela administração dos mesmos, seja pelas empresas prestadoras dos serviços, seja pelos governos. Além disso, os governos, nas empresas que controlam, podem definir preços sem que necessitem seguir qualquer regra.

\section{Economia Política na Fixação de Preços}

Modelos de economia política ${ }^{9}$ partem de premissas que colocam a intervenção governamental como dependente da função objetivo de burocratas e políticos. Normalmente se atribui aos políticos maior utilidade quando estão no governo, logo, maximizarão a possibilidade de sucesso eleitoral. Assim, a busca da eficiência e equilíbrio macroeconômico são objetivos de segunda ordem.

A assimetria de informação dos eleitores com relação às autoridades pode levar a que, enquanto consumidores, possam preferir menores tarifas de água, comunicações, transportes, energia, mesmo pagando mais impostos para financiá-las (muitas vezes não são conscientes de tal fato). Certamente, também preferem menos inflação do que mais, evitando a redução de sua renda disponível.

A função objetivo dos políticos não cria uma estrutura de incentivos para privilegiar a eficiência, pois existe assimetria de informação entre o governo e os funcionários públicos; a busca de maior eficiência não tem impacto eleitoral; os fatores que aumentam o bem-estar dos funcionários públicos têm impacto positivo

\footnotetext{
${ }^{9}$ Vide Vickers e Yarrow (1988).
} 
sobre o ganho do governo, ao passo que o aumento do monitoramento tem efeito contrário.

Essas premissas, em boa parte, devem estar presentes no caso brasileiro. Em particular, o efeito eleitoral positivo de preços públicos baixos e menor inflação. Pesquisas eleitorais mostram a relação entre essas variáveis e intenção de voto, em especial do impacto da inflação.

Além disso, empresas monopolistas, sejam públicas, sejam privadas, têm menores incentivos para atingir a fronteira da eficiência produtiva. No caso brasileiro, essas condições podem se somar para provocar as distorções mencionadas acima. Por exemplo, a Petrobras é um monopólio de fato, não regulado, controlado acionariamente pelo governo federal. Existem portanto, as condições ideais para a manipulação de preços, como se verá a seguir.

\section{O DESAJUSTE DE PREÇOS NO GOVERNO ROUSSEFF}

Há o consenso de que os preços da energia elétrica e do petróleo estão desajustados. O que coloca a questão de saber se existem outros preços administrados atrasados. Há entretanto uma pergunta preliminar: O que são preços atrasados? Como mensurar o atraso?

$\mathrm{Na}$ economia, um preço de equilíbrio de longo prazo, se o mercado fosse perfeitamente competitivo, seria aquele que cobre todos os custos para uma empresa na fronteira de eficiência, inclusive o seu custo de capital que inclui o retorno normal do capital para os acionistas. Ou seja, o preço seria equivalente ao Custo Marginal de Longo Prazo no setor.

Ora, as empresas não são igualmente eficientes, nem os mercados são perfeitamente competitivos. Ainda que fossem "perfeitamente contestáveis", ou seja, com livre entrada e saída, o preço de equilíbrio deveria ser capaz de cobrir os custos totais da empresa menos eficiente, cuja produção seria necessária ao equilíbrio entre oferta e demanda.

Obviamente, estipular tais preços não é tarefa simples e os "atrasos" foram definidos de duas formas: a defasagem dos preços atuais em relação a algum nível de preços praticados no passado recente, ou alguma comparação com o preço praticado hoje com alguma mensuração de preço internacional (para muitas commodities existe preços de referência). Como muitos destes preços são de produtos não tradable, tal comparação não é viável.

Vejamos então o primeiro método, de defasagem em relação a algum preço no passado. Essa ideia foi muito popular no período pré-Plano Real, de altíssima inflação, onde os preços administrados eram, frequentemente, congelados por tempo maior que os preços “livres”. Um trabalho de Werneck (1987) sobre poupança estatal e crise fiscal foi seminal para esta metodologia: para um período de 6 anos, deflacionando os preços do aço, telefonia e energia elétrica pelo IGP-DI, são encontradas perdas de $40 \%, 50 \%$ e $60 \%$ em relação ao preço-base. Na Tabela 2 é realizado um exercício similar. 
Tabela 2: Evolução Preços Administrados IPCA

\begin{tabular}{l|c|c|c}
\hline & $\%$ IPCA & dez-2010 & jun-2014 \\
\hline Preços Administrados & $23,26 \%$ & & \\
\hline Pedágio & $0,12 \%$ & 100 & 113 \\
Óleo diesel & $0,13 \%$ & 100 & 128 \\
Ônibus intermunicipal & $0,72 \%$ & 100 & 121 \\
Emplacamento e licença & $0,99 \%$ & 100 & 103 \\
Gás de botijão & $1,09 \%$ & 100 & 115 \\
Telefone fixo & $1,37 \%$ & 100 & 94 \\
Taxa de água e esgoto & $1,55 \%$ & 100 & 126 \\
Ônibus urbano & $2,63 \%$ & 100 & 118 \\
Energia elétrica residencial & $2,67 \%$ & 100 & 94 \\
Plano de saúde & $3,14 \%$ & 100 & 132 \\
Produtos farmacêuticos & $3,48 \%$ & 100 & 119 \\
Gasolina & $3,86 \%$ & 100 & 114 \\
Sub-total & $22,88 \%$ & & \\
IPCA & & 100 & 124 \\
IPC-M (FGV) & & 100 & 124 \\
\hline
\end{tabular}

Fonte: IBGE via Tendências Consultoria Integrada.

Utilizando a estrutura de preços do IPCA, medida oficial de inflação, na qual os preços administrados representam hoje $23,26 \%$ do total, como se viu na Tabela 1 , são escolhidos os principais itens, que representam 22,88\% do total. Dois preços não têm tanta importância na ponderação, mas foram incluídos pela sua relevância econômica (pedágio e óleo diesel). Faltaria incluir ainda o preço da nafta, matéria-prima essencial da indústria petroquímica, e a energia elétrica industrial, mas elas não estão diretamente na estrutura do IPCA.

Estes preços foram divididos em 4 grupos: Telefonia e Saneamento; Saúde; Energia e Transportes. Utilizando como base 100, o valor de dez/2010, último mês do governo Lula temos a variação acumulada até jun/2014. Para uma variação do IPCA de $24 \%$ (a mesma do IPC-M da FGV), temos variações acumuladas que vão de aumento de 34\% para os Planos de Saúde até 6\% para Telefonia Fixa e Energia Residencial. Estariam os primeiros "caros" e os segundos "defasados"? Essa é a ideia que entendemos como incorreta. Entretanto, em primeiro lugar, vejamos a evolução dos preços administrados em quatro gráficos, pelos quais se compara a evolução dos quatro setores mencionados acima com a variação do IPCA ${ }^{10}$.

\footnotetext{
${ }^{10} \mathrm{Na}$ verdade, sabemos que estamos comparando uma parte do IPCA, os preços administrados, entretanto, o IPCA tem uma evolução temporal equivalente à do IPC-M da FGV, de forma que preferimos manter a comparação com o IPCA, que é a mensuração oficial da inflação, e é o índice que interessa às autoridades manipular.
} 
Evolução Preços Administrados IPCA — Telecom e Saneamento

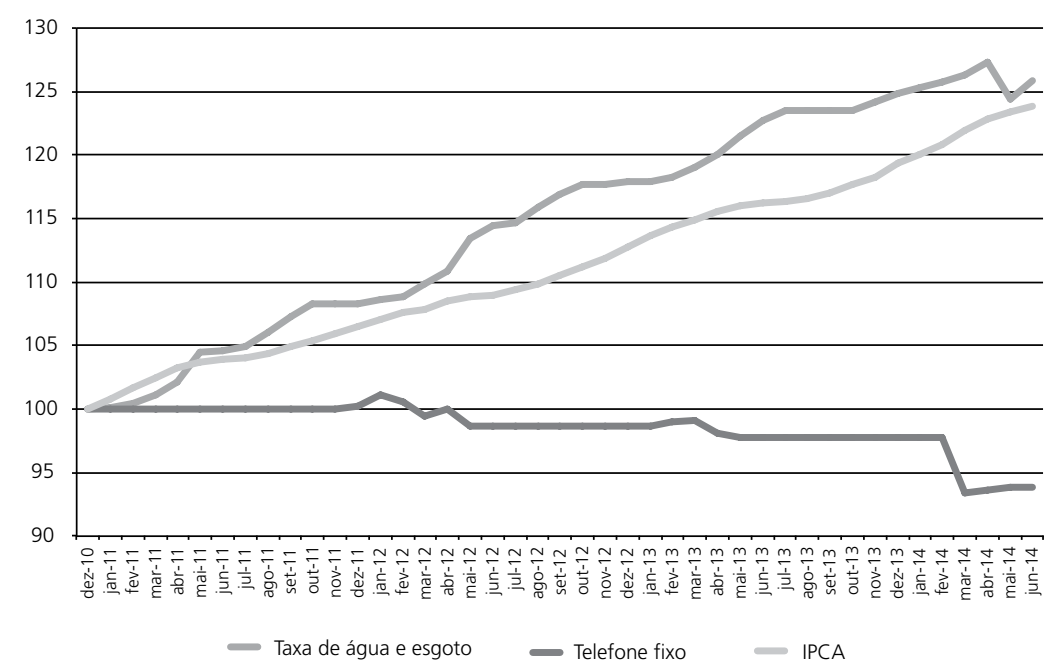

As taxas de água e esgoto são definidas no nível municipal ou estadual. Sua evolução é ligeiramente superior à do IPCA, e à primeira vista aponta a inexistência de defasagem. Todavia a telefonia fixa, com redução nominal também, não apresenta defasagem, como veremos na próxima seção.

Gráfico 2: Evolução Preços Administrados IPCA — Saúde

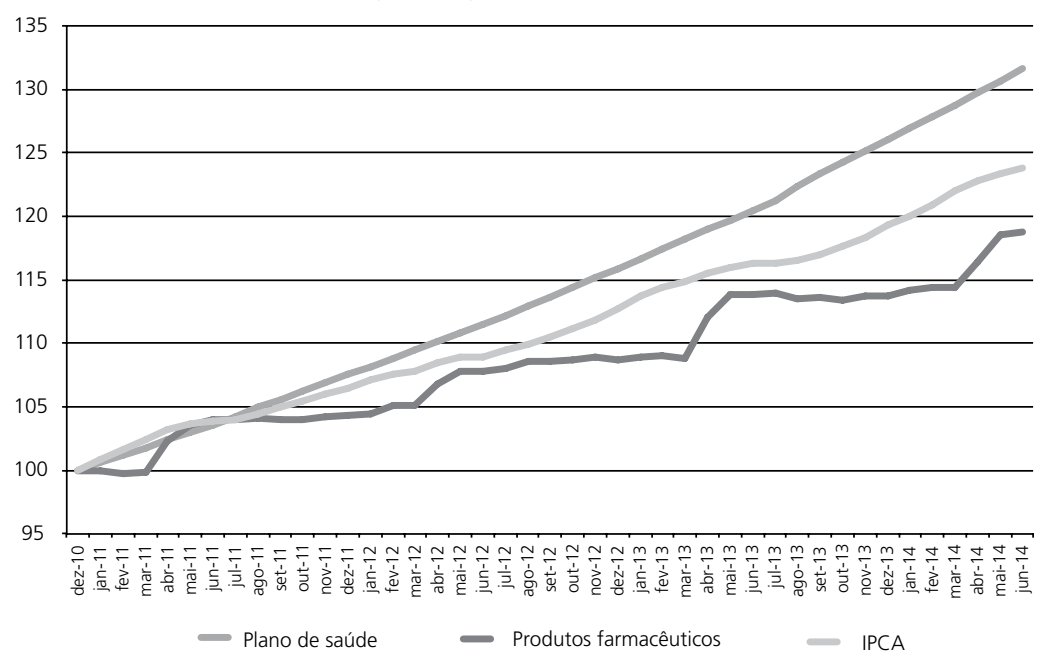

Os planos de saúde apresentaram evolução superior à do IPCA, todavia isso não significa, necessariamente, defasagem, pois tendo em vista o avanço tecnológico na saúde, o custo por vida coberta tende, no mundo todo, a crescer mais do que a renda. Note-se também que hoje a principal modalidade de planos de saúde são 
os planos coletivos, e neles a fixação de preços depende da livre negociação entre operadoras de planos de saúde e pessoas jurídicas que são usuárias. A intervenção da ANS ocorre nos planos de saúde individuais, que têm sido reduzidos devido à imposição de novas obrigações pelos reguladores.

Quanto aos produtos farmacêuticos, eles são - em tese - um setor não regulado no que diz respeito a preços. O controle de preços, como se houvesse um novo CIP, foi estabelecido ainda na gestão Serra no Ministério da Saúde. Um fator que não permite conclusões rápidas é o lançamento de genéricos, o que deprime a média de preços, sem que haja qualquer "defasagem".

Gráfico 3: Evolução Preços Administrados IPCA — Transportes

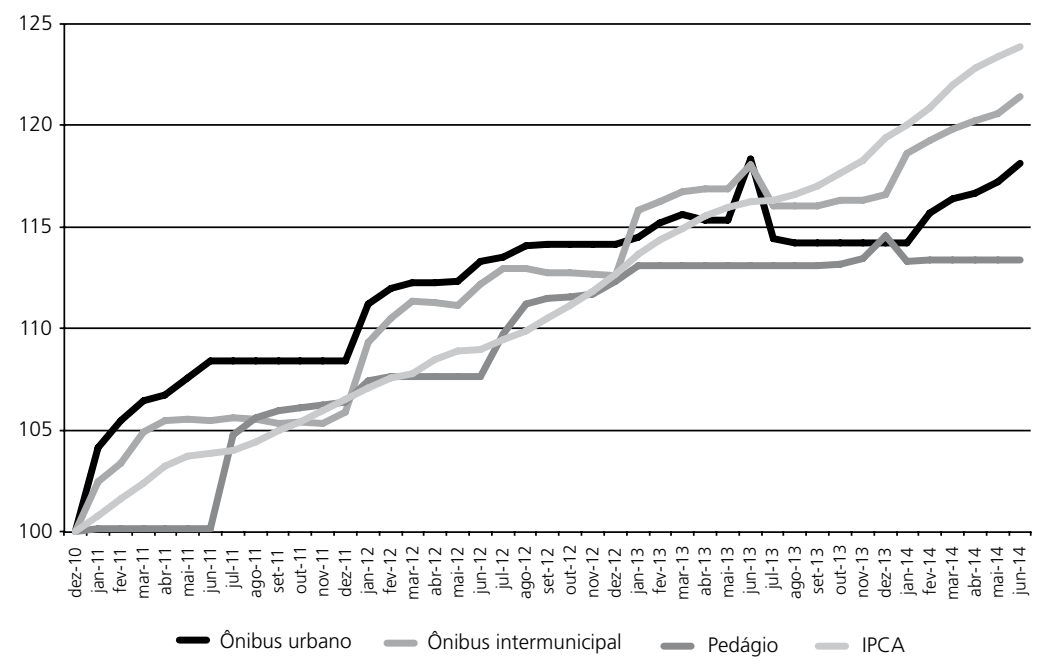

No que se refere aos preços do setor transporte, pode-se observar uma mudança de comportamento em jun-2013. Em função das manifestações populares naquele mês, pedágios que eram reajustados sempre em junho de cada ano mantiveram seus valores nominais fixos, acumulando então uma defasagem. Os pedágios no estado de São Paulo, que são contratualmente reajustados pelo IGP-M, foram congelados pelo governador do estado, que impediu a ARTESP de aplicar o reajuste devido. Ou seja, a "independência" da agência, neste caso, foi anulada. Esta decisão provocou um contencioso judicial a ser resolvido. Há aqui, legalmente, um reajuste contratual represado e que terá de ser resolvido. Talvez com outras medidas que não o simples reajuste dos valores.

Do mesmo modo, os reajustes de ônibus urbanos e intermunicipais, que acumulavam ganhos superiores ao do IPCA, tiveram seus reajustes anulados, com redução nominal das tarifas. Também aqui há uma questão a resolver. No caso municipal, não existe um regulador autônomo, nem o conhecimento das autoridades dos custos do serviço, o que dificulta saber qual é o grau de reajuste "represado". 
Gráfico 4: Evolução Preços Administrados IPCA — Energia

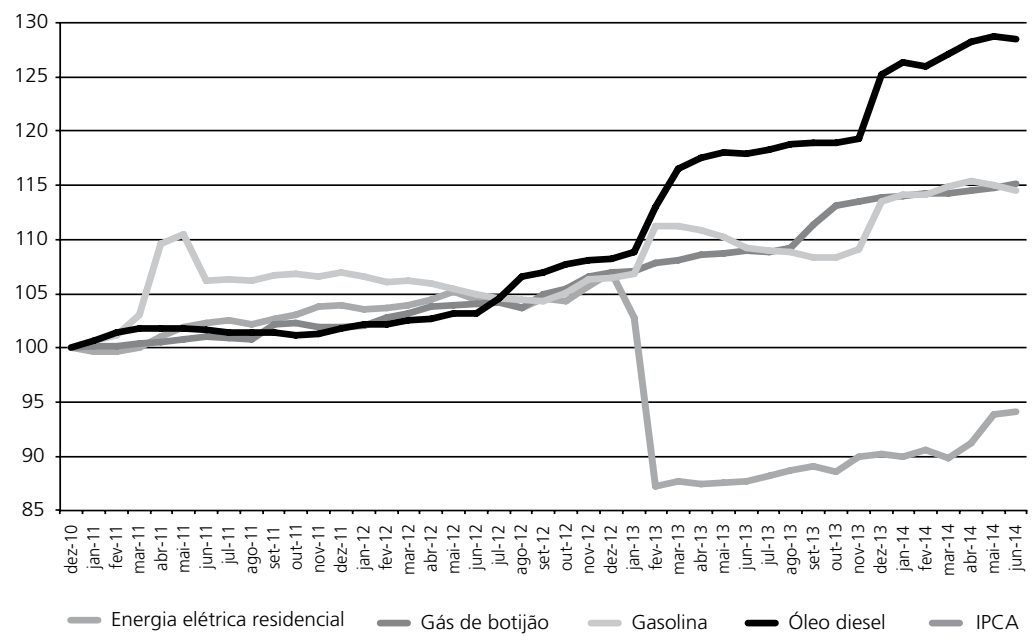

O caso mais grave entretanto, é o dos preços de energia, seja de derivados de petróleo, seja de energia elétrica residencial. No caso da energia elétrica, uma ação voluntariosa da Presidência da República impôs uma renovação de concessões de geração hidroelétrica vincendas em troca de uma redução de preços. A análise dos impactos das medidas impostas não foi realizada de maneira adequada, de forma que incentivou o consumo e provocou, aliado a uma crise na oferta em função de variáveis climáticas, um grande prejuízo às distribuidoras de energia, que vem sendo coberta pelo Tesouro Nacional. A recomposição das tarifas já está programada.

Entretanto, onde a "politização" da definição de preços administrados se mostra mais patente é no de derivados de petróleo. Pode-se observar que o óleo diesel, que representa apenas $0,13 \%$ do IPCA, teve seus preços reajustados em valor semelhante ao do IPCA (28\% contra $24 \%$ no período jan-2011 a jun-2014). Já a gasolina $(3,86 \%)$, o gás de botijão (1,09\%) e a própria energia elétrica residencial $(2,67 \%)$, que têm peso significativo no IPCA (total de 7,62\%), tiveram, ou redução nominal, ou reajuste significativamente abaixo do IPCA, $15 \%$ contra inflação acumulada de $24 \%$. Na inexistência de choques de produtividade, é difícil afastar a hipótese de populismo tarifário para conter a inflação abaixo do "teto da meta" e ganhar lealdades eleitorais.

Vejamos agora até que ponto se pode deduzir a existência de defasagens nos preços administrados cujos reajustes tiveram a maior diferença em relação à variação do IPCA.

\section{CONCLUSÃO: EXISTEM OUTROS PREÇOS DESAJUSTADOS?}

Há o consenso de que os preços da energia elétrica e do petróleo estão desajustados. O que coloca a questão de saber se outros preços administrados estão atrasados. Nas seções anteriores foram apresentadas as dificuldades de fixar preços em setores com poder de mercado e a evolução dos diferentes preços administrados em relação ao IPCA. 
Em primeiro lugar é necessário saber se há indícios de defasagem real de preços e não apenas de reajuste significativamente diferente do IPCA. Caso sim, cabe discutir o rumo da correção e quais as dificuldades de sua implementação. Vejamos então os preços de telefonia, saúde (planos de saúde), transporte (pedágios e ônibus) e energia sob essa ótica.

\section{Telefonia Fixa}

A Lei ${ }^{\circ}$ 9.472, de 16 de julho de 1997, Lei Geral de Telecomunicações, definiu que o STFC deveria ser prestado em Regime Público, o que significou que os preços ao usuário final seriam definidos pela ANATEL. Conforme o Contrato de Concessão de STFC, as tarifas constantes do Plano Básico do Serviço Local (que é uma cesta de serviços que abrange o valor da assinatura, da ligação local e outros), utilizado pela imensa maioria dos usuários, pode ser reajustado a cada 12 meses. Inicialmente pelo IGP-DI, mas, a partir de 2006, os contratos de concessão da telefonia fixa e da Exploração Industrial de Linha Dedicada passaram a ser reajustados pelo Índice de Serviços de Telecomunicações (IST), que apresenta variação menor do que o IPCA.

A ANATEL passou a utilizar um fator de produtividade na fórmula do reajuste dos valores dos planos básicos. Esse fator (Fator X) é o ganho advindo da utilização de novas tecnologias e novas metodologias de produção na telefonia fixa, que é diminuído do valor do IST. O valor do reajuste tem se aproximado de zero. O Quadro 1 mostra os valores do Fator X a partir de 2009.

\begin{tabular}{l|llll}
\multicolumn{5}{c}{ Quadro 1: Fator X definido pela ANATEL } \\
\hline \multirow{3}{*}{ Fator X } & 2009 & 2010 & 2011 & 2013 \\
\hline & $3,90 \%$ & $3,73 \%$ & $3,59 \%$ & $4,26 \%$ \\
\hline
\end{tabular}

Fontes: ANATEL e Telecom.

Gráfico 5: Evolução de Assinantes de STFC

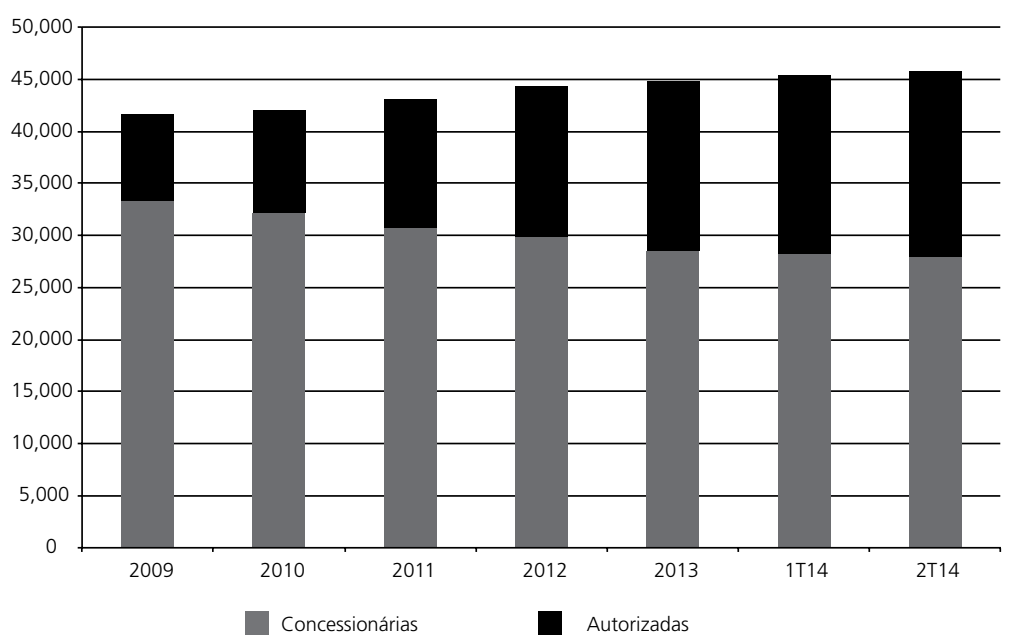

Fontes: ANATEL e Telecom. 
Apesar de reajustes próximos de zero após o desconto do Fator X, não se pode afirmar que exista "defasagem" de preços. O maior indício é a perda de $m a$ rket share das Concessionárias de STFC, pois as empresas autorizatárias de telefonia fixa (NET, GVT, etc.) praticam preços significativamente menores que as concessionárias. O Gráfico 5 mostra como, apesar do aumento do número de assinantes de telefonia fixa, as Concessionárias tem redução absoluta de assinantes e de market share, o que indica preços mais elevados que a concorrência.

\section{Planos de Saúde}

A Lei ${ }^{\circ}$ 9.961, de 28 de janeiro de 2000, que criou a Agência Nacional de Saúde Suplementar - ANS, não conferiu competência para "autorizar reajustes e revisões das contraprestações pecuniárias dos planos privados de assistência à saúde" (essa competência foi explicitamente retirada da lei). Todavia, a Lei dos Planos de Saúde conferiu à ANS esta competência para os novos planos individuais.

Existem os seguintes tipos de planos de saúde:

1) Individual ou familiar: contrato assinado entre um indivíduo e uma operadora para assistência à saúde do titular (individual) ou do titular e seus dependentes (familiar).

2) Coletivo com patrocinador: planos contratados por pessoa jurídica com mensalidade total ou parcialmente paga às operadoras pela contratante.

3) Coletivo sem patrocinador: planos contratados por pessoa jurídica, com mensalidade integralmente paga pelo beneficiário diretamente à operadora.

Os planos coletivos estabelecem seus preços em negociações entre as operadoras de planos de saúde e as pessoas jurídicas que compram tais planos, em negociações anuais. Já os planos individuais (com pessoas físicas) têm seus reajustes definidos pela ANS, que tem aplicado reajustes menores do que o dos planos coletivos. A ANS pode definir também a abrangência da cobertura dos planos, em particular dos planos individuais. Abrangência que tem se ampliado sem contrapartidas financeiras. O resultado é que as grandes operadoras de planos de saúde deixaram de ofertar planos individuais, e seu número estagnou, embora o número total tenha crescido 4,5\% a.a. entre 2003 e 2013, como se pode notar no Gráfico 6 a seguir.

A defasagem dos preços dos planos individuais, contudo, poderá não provocar qualquer efeito macroeconômico. A tendência é que os planos individuais desapareçam com o correr do tempo.

\section{Transportes}

No caso de transportes, os dois preços que se tornaram defasados a partir das manifestações de jun-2013 são pedágios e ônibus urbano. Ambos os serviços estão sujeitos à Lei $\mathrm{n}^{\circ}$ 8.987, de 13 de fevereiro de 1995, de Concessões de Serviços Públicos, que obriga à manutenção do equilíbrio econômico-financeiro do contrato. 


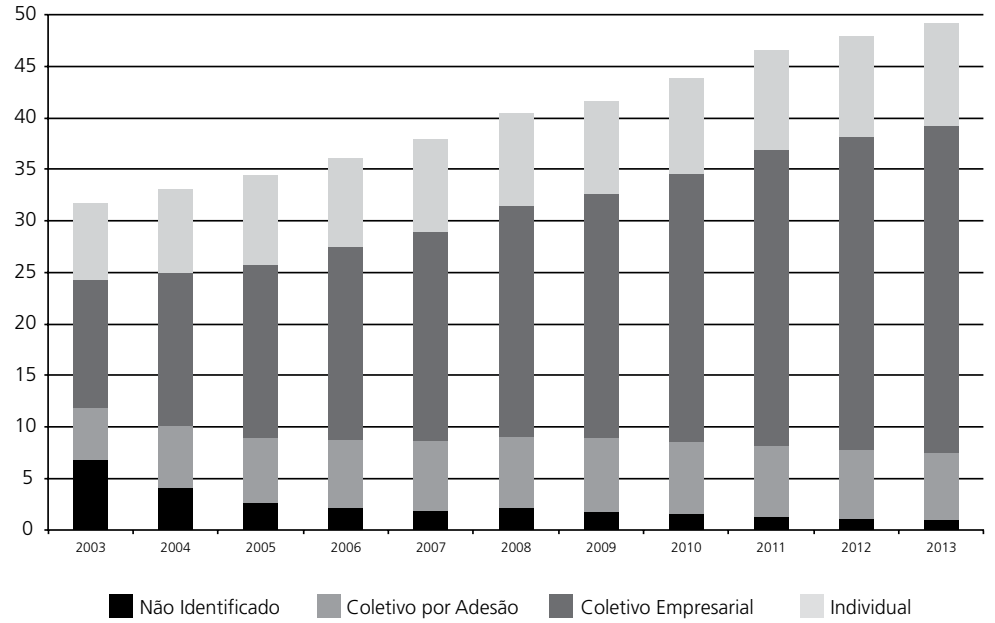

Fontes: IESS e ANS.

Os preços devem ser fixados em função daquele objetivo e da modicidade tarifária. Os instrumentos para tal são o reajuste e a revisão das tarifas.

Os reajustes eram cumpridos até junho de 2013, quando foram congelados. Houve uma paralisia da administração pública em função do movimento político daquele ano. Os Executivos estaduais e municipais preferiram aceitar a reivindicação de não aumento de tarifas.

Há, portanto, no caso do pedágio, um passivo judicial a ser resolvido, pois o contrato de concessão obriga ao reajuste. No caso municipal, como muitas vezes existe uma diferença entre a tarifa paga pelo usuário e o valor recebido pelas empresas de ônibus, o congelamento da tarifa implicou um aumento de subsídio.

O problema maior aqui, em termos de impacto, envolve uma variável política de saber se os contratos serão seguidos daqui para a frente. Um segundo problema diz respeito a como fazer a recomposição dos aumentos de 2013 que foram postergados. A existência de uma agência reguladora que trabalhe com transparência, utilizando audiências públicas de maneira mais intensiva, pode ajudar a resolver a aceitação da legitimidade das tarifas. Além disso, ela poderia iniciar um processo de revisão tarifária para tornar claros os custos efetivos do serviço. Finalmente, existe um problema macroeconômico no sentido de que haverá algum impacto sobre a inflação com a recomposição. Todavia, a manutenção da defasagem em relação ao contrato significa um desincentivo ao investimento e/ou redução da qualidade do serviço.

\section{Energia}

Finalmente, em relação aos preços de energia elétrica e derivados de petróleo, que no painel se partiu da hipótese da existência de preços reprimidos, também 
neste caso haveria que se questionar o "ajuste" de preços como mera elevação em relação a algum patamar de preços no passado.

Devem ser considerados os seguintes fatores:

a) Os mercados de energia são interligados: para as empresas, interessa no longo prazo a relação BTU/US\$ de cada insumo energético. Assim, gás natural, energia elétrica, óleo combustível e carvão são substitutos.

b) Há uma revolução energética em curso com a exploração do gás de xisto com fracking (embora existam dúvidas sobre o seu alcance e impactos ambientais).

c) A PETROBRAS continua sendo um monopolista de fato, com integração vertical: domina toda a infraestrutura de dutos e portuária para importação de gás e derivados de petróleo.

d) A ANP continua sendo fraca ante o poderio da PETROBRAS e absolutamente pusilânime quanto ao domínio da infraestrutura, além de dificultar a construção de novas rotas e de demorar com as licenças para exploração de novas fontes de gás (inclusive de xisto).

Assim, embora exista uma necessidade de recompor o equilíbrio econômico-financeiro da PETROBRAS e do setor elétrico, haveria de se pensar a recomposição dos preços relativos dos insumos energéticos em função da necessidade da competitividade da economia brasileira. Neste sentido, descentralizar as licenças para a exploração de gás e a construção de dutos interestaduais, além de separar funcionalmente a operação da infraestrutura da PETROBRAS, é essencial para atingir e manter o equilíbrio macroeconômico e a competitividade brasileira.

\section{REFERÊNCIAS BIBLIOGRÁFICAS}

Armstrong, M.; Cowan, S. and Vickers, J. (1994) Regulatory Reform: Economic Analysis and British Experience. London, MIT Press.

Atkinson, R. C. "Market Structure for Ultrabroadband”. Communications \& Strategies, Special issue, November.

Averch, H. and Johnson, L.L., (1962) "Behavior of the firm under regulatory constraint". American Economic Review, 52:1052-69.

Bailey, E., (1987) Public Regulation: New Perspectives on Institutions and Policies. Cambridge (Mass.): MIT Press.

Barrionuevo, A. e Lahera, E. (1997) Qué Hay de Nuevo en las Regulaciones? Telecomunicaciones, Electricidad y Agua en América Latina. Buenos Ayres: EUDEBA.

Bishop, M.; Kay, J. and Mayer, C. (1994) Privatization and Economic Performance. Oxford: Oxford University Press.

Cave, Martin E., Majumdar, Sumit K. and Vogelsang, Ingo. (2002) Handbook of Telecommunications Economics. Amsterdam, Elsevier, volume 1.

Cave, Martin E., Majumdar, Sumit K. and Vogelsang, Ingo. (2005) Handbook of Telecommunications Economics. Amsterdam, Elsevier, volume 2.

Economides, N. (2005) "Hit and miss: leverage, sacrifice, and refusal to deal in the supreme court decision in Trinko". Working Paper \#05-32, www.NETinst.org, December. 
Economides, N.(2006) "Public policy in network industries. NET Institute”, Working Paper \#06-01, http://www.NETinst.org.

Ezell, S.; Atkinson, R.; Castro, D. and Ou, G. (2009) "The need for speed: the importance of next-generation broadband networks". The Information Technology \& Innovation Foundation, March.

Farrell, J. and Weiser, P.J. (2004) "Modularity, vertical integration, and open access policies: towards a convergence of antitrust and regulation in the internet age". Harvard Journal on Law and Technology.

Frischmann, B. e Waller, S. W. (2006) “Essential facilities, infrastructure and open access". http://www. $\mathrm{ftc}$.gov/os/comments/section2hearings/522292-00013.pdf, s.d.

Gentzoglanis, A. e Aravantinos E. (2008) "Forecast models of broadband diffusion and other information technologies". Communications \& Strategies, Special issue, November.

Joskow, P.L. and Rose, N.L., (1989), “The effects of economic regulation”. In Schmalensee, R. et alii, Handbook of Industrial Organization. New York: Elsevier Science Publishers.

Kerf, M; Neto I. and Geradin, D. (2006) “Antitrust vs. sector-specific regulation: what works best? “ www.ssrn.org, 2006.

Laffont, J. and Tirole, J. (1993) A theory of incentives in procurement and regulation. Cambridge: MIT Press, 1993.

Liebowitz, S. and Margolis, S. (2002) “Network effects”. In Cave, M.E.; Majumdar, S.K. and Vogelsang, I. (ed.) Handbook of Telecommunications Economics. Amsterdam: Elsevier Science, Volume 1.

Maluf, E. (2011) “O controle de preço de medicamentos”. Revista de Direito Sanitário, v. 12, n. 1 p. 67-84 Mar./Jun.

Mattos, C. (2007) A Proposta do Governo em Interconexão e Unbundling na Renovação dos Contratos de Concessão em Telecomunicações em 2006. mimeo, 2007.

Phillips Jr., C.F. (1993) The Regulation of Public Utilities. Arlington (Virginia): Public Utilities Reports Inc.

Vickers, J. and Yarrow, G. (1988) Privatization: An Economic Analysis. Cambridge (Mass.), MIT Press, Viscusi, W.; Harrington, J. and Vernon, J. (2005) Economics of Regulation and Antitrust. Cambridge Massachusetts, MIT Press.

Werneck, R.F., (1987), “Poupança estatal, dívida externa e crise fiscal”. In Lozardo, E. (Org.), Déficit Público Brasileiro: Política Econômica e Ajuste Estrutural. Rio de Janeiro: Paz e Terra. 